UCRL-ID-119660

\title{
Advanced Microinstrumentation for Rapid DNA Sequencing and Large DNA Fragment Separation
}

\author{
J. Balch \\ J. Davidson \\ L. Brewer \\ J. Gingrich \\ J. Koo \\ R. Mariella \\ A. Carrano
}

January 25, 1995

This is an informal report intended primarily for internal or limited external distribution. The opinions and conclusions stated are those of the author and may or may not be those of the Laboratory.

Work performed under the auspices of the U.S. Department of Energy by the Lawrence Livermore National Laboratory under Contract W-7405-ENG-48. 


\section{DISCLAIMER}

This document was prepared as an account of work sponsored by an agency of the Linited States Gorernment. Neither the United States Government nor the University of California nor any of their employes, makes any warranty, express or implied, or assumes any legal liability or responsibility for the accuract, completeness, or usefulness of any information, apparatus, product, or process disclosed, or represents that its use would not infringe privatejy owned rights. Reference herein to any specific commercial products, process, or service by trade name, trademark, manufacturer, or otherwise, does not necessarily constitute or imply its endorsement, recommendation, or favoring by the United States Government or the University of California. The riews and opinions of authors expressed herein do not necessarily state or reflect those of the United States Government or the University of California, and shall not be used for advertising or product endorsement purposes.

This report has been reproduced directly from the best 2vailable copy.

Available to DOE and DOE contractors from the

Office of Scientific and Technical Information

P.O. Box 62, O2k Ridge, TN 37831

Prices available from (615) 576-8401, FTS 626-8401

Available to the public from the

National Technical Information Service

US. Department of Commerce

5285 Port Rojal Rd.

Springfield, VA 22161 


\section{DISCLAIMER}

Portions of this document may be illegible in electronic image products. Images are produced from the best available original document. 


\title{
Advanced Microinstrumentation for \\ Rapid DNA Sequencing and Large DNA Fragment Separation
}

Joseph W. Balch, J. Courtney Davidson, Larry Brewer, Jeff Gingrich, Jackson C. Koo, Ray Mariella, and Anthony V. Carrano

\begin{abstract}
Our efforts to develop novel technology for a rapid DNA sequencer and large fragment analysis system based upon gel electrophoresis are described. We are using microfabrication technology to build dense arrays of high speed micro electrophoresis lanes that will ultimately increase the sequencing rate of DNA by at least 100 times the rate of current sequencers. We have demonstrated high resolution DNA fragment separation needed for sequencing in polyacrylamide microgels formed in glass microchannels. We have built prototype arrays of microchannels having up to 48 channels. Significant progress has also been made in developing a sensitive fluorescence detection system based upon a confocal microscope design that will enable the diagnostics and detection of DNA fragments in ultrathin microchannel gels. Development of a rapid DNA sequencer and fragment analysis system will have a major impact on future DNA instrumentation used in clinical, molecular and forensic analysis of DNA fragments.
\end{abstract}
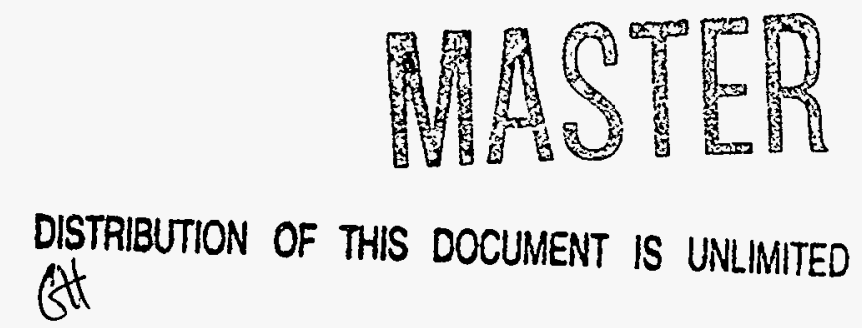


\section{Introduction}

Most clinical, molecular, or forensic projects that involve the characterization of DNA are dependent upon the separation and/or purification of DNA fragments by one or more methods. By far, the most common method is based upon electrophoresis. Since the DNA double-helix backbone is negatively charged, fragments of DNA migrate toward the anode when placed in an electric field. If the DNA is caused to migrate through a sieving matrix such as agarose or polyacrylamide, fragment mobility is a function of fragment size, i.e. the smaller fragments migrate faster than larger fragments. The different sieving matrices available and methods of applying the electric field offer variables for adapting the electrophoresis procedure to suit specific needs.

The techniques of DNA sequencing (the process of determining the order of nucleotides in a DNA molecule) and large DNA fragments analysis are both highly valued by many clinical, molecular biology and forensic projects. Sequencing the human genome will help provide an understanding and potential treatment of genetic disorders. For example, genes for the following disorders have recently been identified: Multiple Sclerosis, Amyotrophic Lateral Sclerosis, and Huntington's disease. Typical applications of fragment analysis and collection include: 1 ) restriction fragment analysis to trace disease-associated DNA polymorphisms through family members: 2) DNA fingerprinting to detect common fragments in the evaluation of DNA identity for forensics or to establish commonalty between cloned segments of DNA; and 3) Southern analysis which involves the hybridization of molecular probes onto the separated DNA fragments to determine the precise location of a gene of interest.

Major limitations of current DNA electrophoresis analysis systems include the time required to run a sample by electrophoresis and the number of electrophoresis channels (lanes) that can be run simultaneously. For example, the separation of double-stranded (undenatured) DNA fragments in the range of about 100 to 20,000 base pairs (bp) are best fractionated by embedding them in an agarose gel sieving matrix and applying a constant voltage across the gel. Such electrophoretic separations usually take about 2-12 hours. Likewise, DNA sequence analysis in an Applied Biosystems (ABI) Model 373 automated DNA sequencer requires approximately 10 hours to separate and identify 500 bases of sequence information per lane. Typically fragments are run in up to 36 parallel lanes. Thus, this state-of-the-art commercial DNA sequencer has a maximum throughput of 1800 bases per hour. At this rate, more than 1.7 million hours of separations will be required to sequence the 3 billion bases in the human genome--assuming $100 \%$ yield and not allowing for any repeat experiments. The time and cost for DNA sequencing must be reduced before the agencies funding the Human Genome project will provide any significant funding support for sequencing.

For some time it has been recognized 1,2 that the use of thinner gels in electrophoresis would allow faster separations. Current DNA sequencers such as the ABI 373 use $0.3-0.4 \mathrm{~mm}$ thick slab gels which have relatively poor thermal dissipation of the joule heating created by the current flow in the gel. To limit the thermal dispersion of the separated fragments in these gels, the temperature variation across the thickness of the gel must be less than $1{ }^{\circ} \mathrm{C}$ which requires limiting the electric field to a maximum of approximately $50 \mathrm{~V} / \mathrm{cm}$ in conventional slab gel instruments. By doing the separations in thinner gels whose joule heating can be more quickly dissipated, the electric field can be increased, resulting in shorter separation times. The advantages of thinner gels in allowing high-speed separations of DNA from sequencing reactions has recently been demonstrated by several groups using gel-filled capillary electrophoresis. In 
gel capillary electrophoresis, the separation is typically done in a 50-100 um internal diameter quartz capillary which has much improved thermal dissipation over thicker slab gels. For example, using a $50 \mathrm{um}$ i.d. capillary operated at an electric field of $200 \mathrm{~V} / \mathrm{cm}$, Drossman et. al. ${ }^{3}$ demonstrated a ten- fold reduction in separation time of a DNA sample compared to the separation time required for the same sample using the ABI 373 DNA sequencer operated with a 400 um thick slab gel and run with a $30-37.5 \mathrm{~V} / \mathrm{cm}$ applied electric field. Efforts to develop high-speed, high throughput automated DNA sequencers by combining many small diameter quartz capillaries (e.g. 10-100) have experienced many mechanical and electrical problems concerned with: 1) filling multiple capillaries with equally high quality gel; 2) loading the DNA samples into separate capillaries; and 3) devising a sensitive optical detection system to measure the output fluorescence signals from all the very small capillaries. Other major factors limiting resolution of DNA fragments by electrophoresis include sample quality, sample loading on to the gel, and diffusion of DNA through the gel prior to the time of detection.

We are developing a rapid DNA sequencing and large fragment analysis technology based upon gel electrophoresis. Described below are technologies 1) to build a high density array of electrophoresis lanes on a single substrate for DNA sequencing and large fragment separation and 2) ultra sensitive fluorescence detection system to image the DNA fragments in microchannels. Ultimately the microfabrication techniques we are using will allow us to construct 200 microchannels, each 50 micron wide 50 micron deep and spaced 150 microns apart, in a $4 \mathrm{~cm}$ by $25 \mathrm{~cm}$ area of an electrophoresis plate. These technologies are applicable to both DNA sequencing and fragment analysis and have been developed in parallel.

\section{Microfabrication Techniques}

\subsection{DNA Sequencing}

Using micromachining technologies we are building high density arrays of electrophoresis microchannels in glass substrates. Figure 1 shows the conceptual diagram of a high density array of electrophoresis microchannels etched on a glass or other insulating substrate. The microchannels are filled with a thin electrophoresis gel and the whole assembly is covered by a optical quality plate that will transmit the laser-induced fluorescence of the fluorochrome labeled DNA fragments onto a sensitive optical detector.

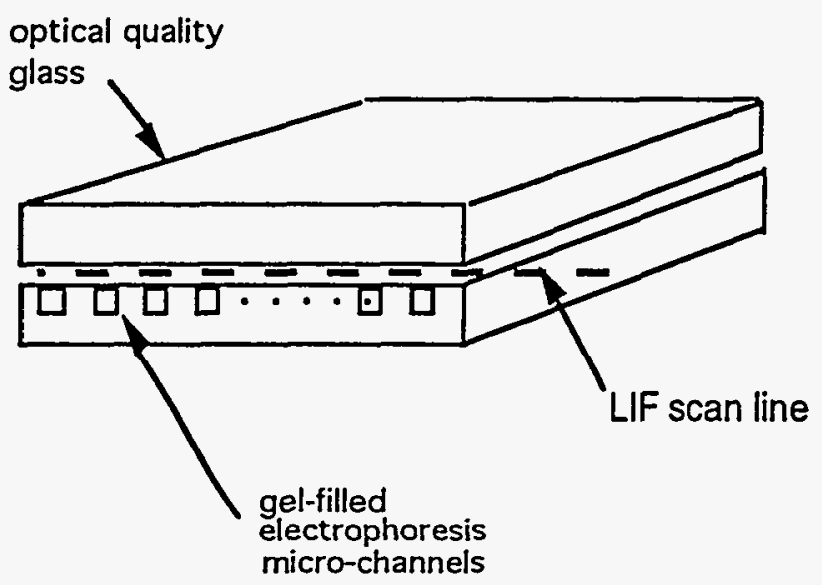

Figure 1. Diagram showing an array of microchannels in one glass electrophoresis plate. The microchannels are filled with a sieving gel and covered with a top glass plate whose optical transmission properties will allow detection of fluorochrome labeled DNA fragments via laser induced fluorescence. 
We have explored a number of techniques for building microchannels in glass substrates for electrophoresis of DNA. Techniques investigated included 1) ultrasonic milling, 2) ultrasonic milling plus mechanical polish, 3) ultrasonic milling plus a final wet chemical polish, and 4) wet chemical etching. Table 1 compares the measured electrophoresis resolution and measured surface roughness for microchannels fabricated by the different methods. These results indicate that electrophoresis resolution depends upon the surface finish. Both chemical etching and ultrasonic milling with mechanical polishing methods produced microchannels having resolutions comparable to that of polished glass plates used for standard slab gel electrophoresis. We have determined that chemical etching is an efficient way to fabricate high density arrays of microchannels on a single substrate with good depth control and produces the surface finish required for good electrophoresis resolution.

Table 1. Results obtained for electrophoresis resolution for different fabrication methods of microchannels in glass. The electrophoresis resolution is correlated with the RMS surface roughness measured for the different fabrication methods. *Electrophoresis resolution is defined as the spacing between adjacent fragments divided by their average half maximum width.

\begin{tabular}{|l|c|c|}
\hline \multicolumn{1}{|c|}{ Fabrication Method } & $\begin{array}{c}\text { RMS Surface Finish } \\
\text { (micro-meters) }\end{array}$ & $\begin{array}{c}\text { DNA Fragment Length } \\
\text { (base) } \\
\text { @ Resolution*=1 }\end{array}$ \\
\hline Polished glass (Std) & $0 .()(1)$ & 510 \\
\hline Ultrasonic mill & 3.0 to 4.0 & 145 \\
\hline $\begin{array}{l}\text { Ultrasonic mill }+ \\
\text { chemical polish }\end{array}$ & 0.41 & 485 \\
\hline $\begin{array}{l}\text { Ultrasonic mill + } \\
\text { mechanical polish }\end{array}$ & 0.01 & 480 \\
\hline \begin{tabular}{l} 
Chemical etch \\
\hline
\end{tabular}
\end{tabular}


Using the chemical etching technique we built various arrays of microchannels for sequencing experiments. Figure 2 shows a sequencing plate with 48 etched microchannels (200 um deep, $1.25 \mathrm{~mm}$ wide and a $25 \mathrm{~cm}$ load-to-read distance). The electrophoresis resolution in these channels was characterized for standard $6 \%$ polyacrylamide gel run at an approximate electric field strength of $40 \mathrm{~V} / \mathrm{cm}$. Figure 3 shows an example electropherogram of four color sequencing of a DNA Taq standard used to verify sequencing resolution. The laser induced fluorescence signal from the dye-labeled DNA fragments was collected on a modified Applied Biosystem 373 detection and data analysis system. Good sequencing resolution and base calling was achieved for the first 500 bases with a base calling error rate of less than $3 \%$.

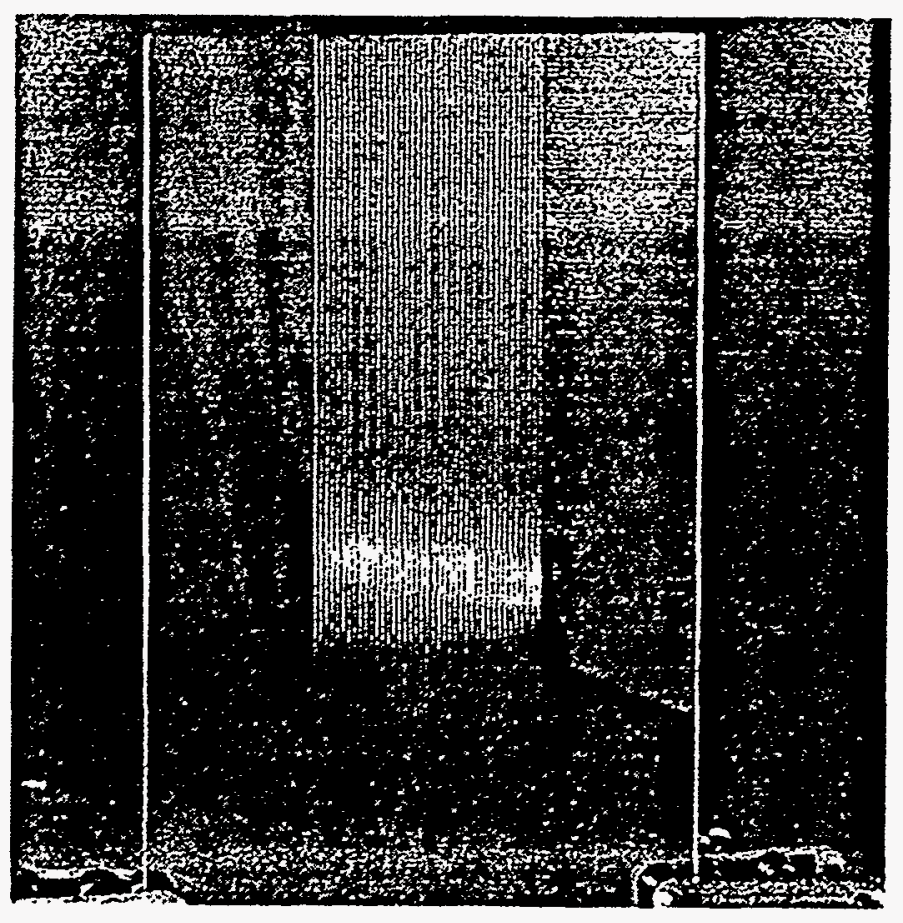

Figure 2. A glass electrophoresis plate with 48 etched microchannels which are $200 \mathrm{um}$ deep, $1.25 \mathrm{~mm}$ wide, with $1.25 \mathrm{~mm}$ spacing, and $25 \mathrm{~cm}$ load-to-read distance. 


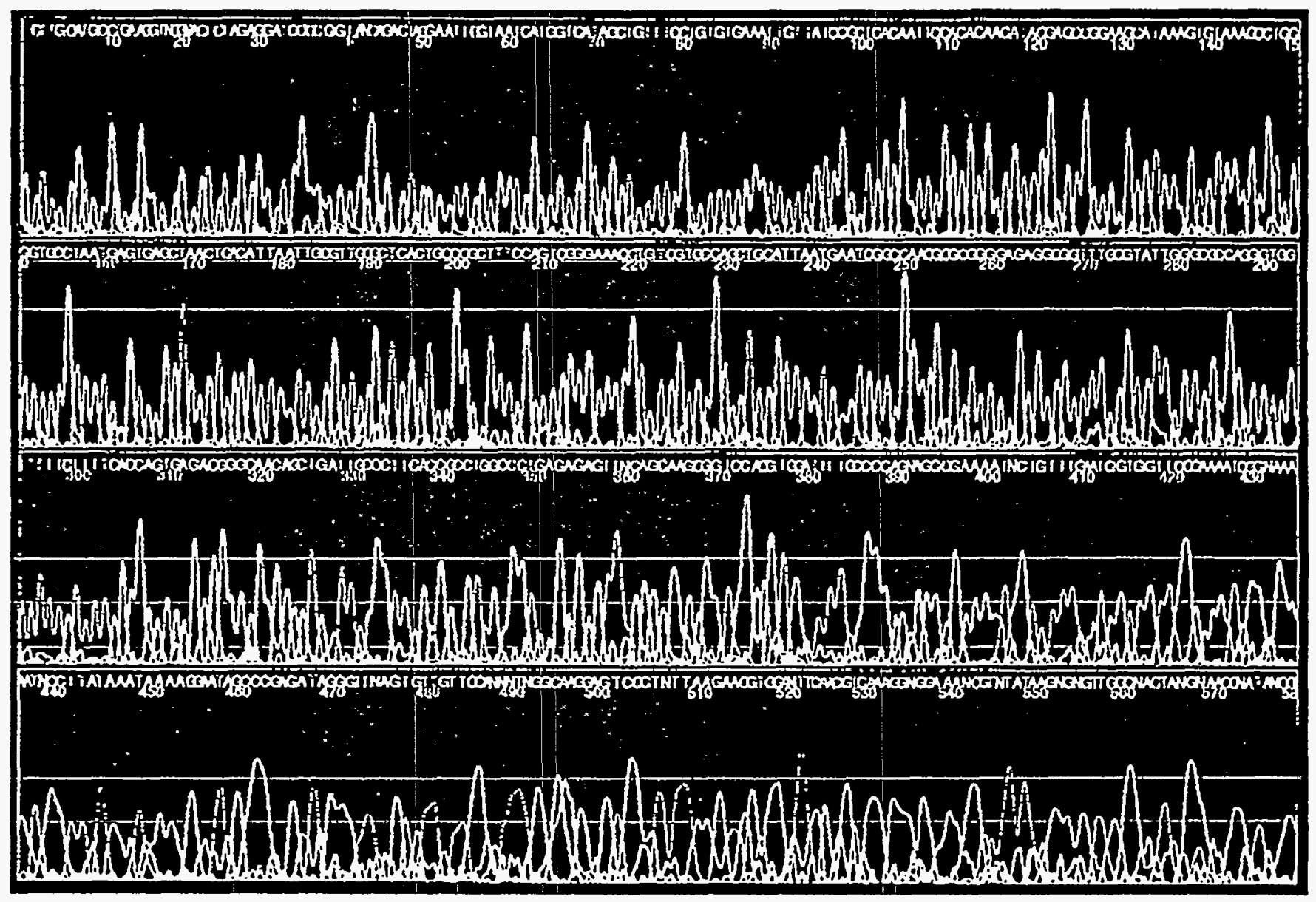

Figure 3. Electropherogram of $\mathrm{M} 13 \mathrm{mp} 18$ Taq sequencing standard with four color dyes as obtained in microchannels etched in glass substrate.

\subsection{Large Fragment Analysis.}

We have pursued two approaches for improved DNA fragment analysis:

1) microchannel plates for increased samples throughput per given run and 2) novel alternative gels for increased resolution.

We have built several electrophoresis plates for experimental work done on a commercial DNA separation instrument. We have manufactured forty eight 1 millimeter wide channels in both glass and in acrylic. We have obtained results comparable to standard $4 \mathrm{~mm}$ thick agarose slab gels out to about $20 \mathrm{~K}$ base pairs on an Applied Biosystems model 362 Gene Scanner with a modified gel compartment to house our custom electrophoresis plates. Figure 4 shows a comparison of electropherograms from a) a standard slab gel, b) a glass microchannel, and c) a plastic microchannel. A Applied Biosystems Genescan-30000 DNA fragment size standard that consists of 14 arbitrary fragment lengths from 165 to 27,531 base pairs was used to compare results. Our channel gels $(0.8 \%$ agarose) run with an electric field strength of about 10 volts/cm have ranged from 2 to $4 \mathrm{~mm}$ thick. These results indicate that glass microchannels resolve all fragments with resolution comparable to the standard slab system while the plastic microchannels did not resolve the larger fragments as well. This may be due in part to the increased thermal dissipation of glass. The micromachined glass channels were one-filth the width of the standard electrophoresis lanes resulting in $5 \mathrm{X}$ the packing density of electrophoresis lanes. 


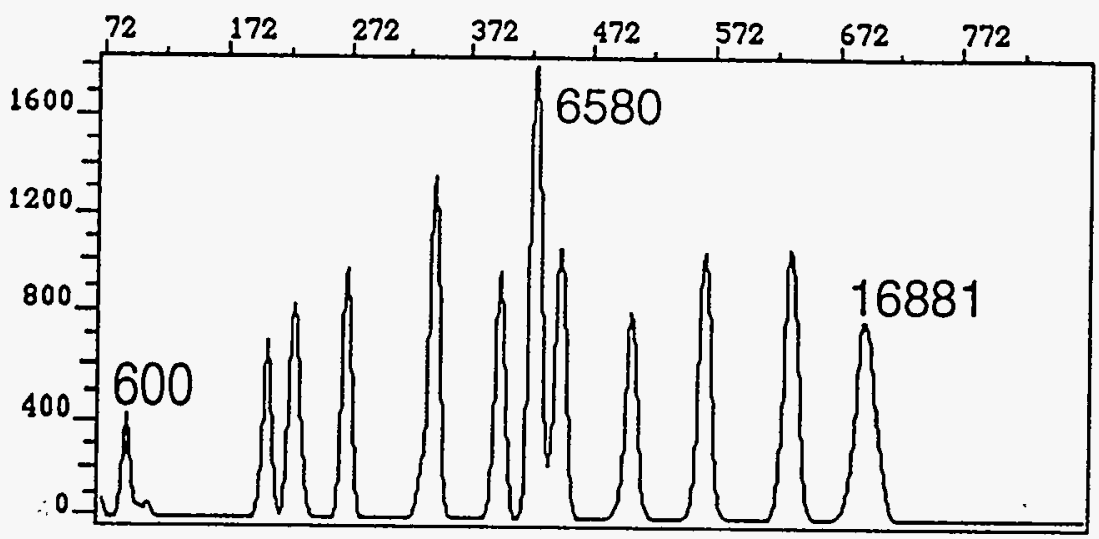

a Lane 2: GS-30,000

(a)

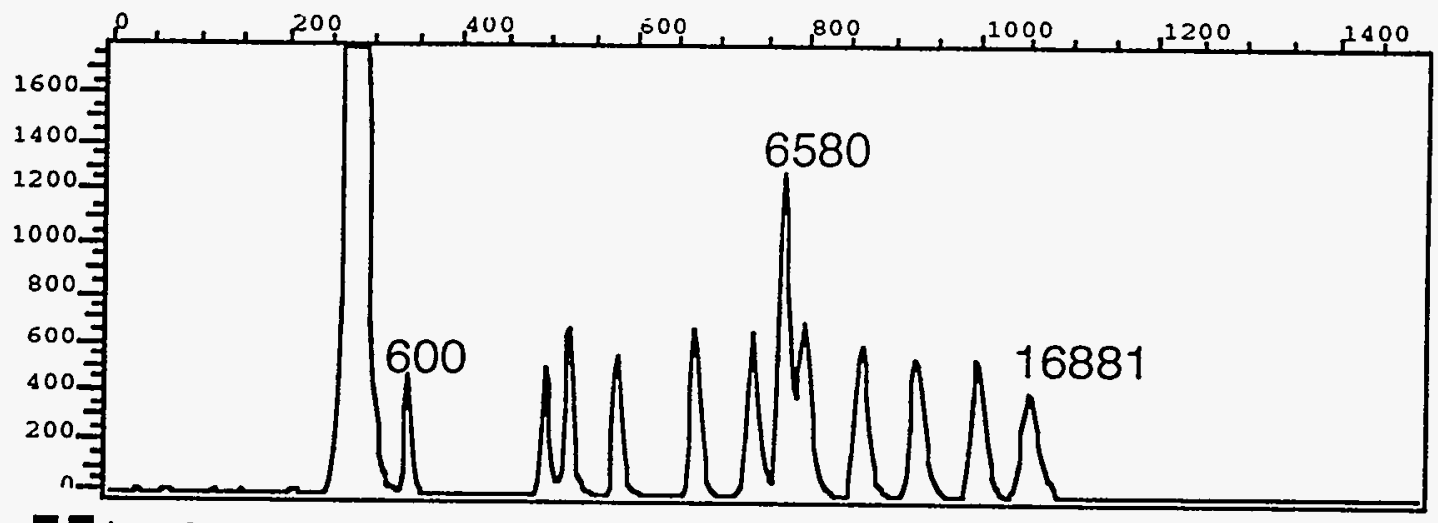

므 Lane 8:

(b)

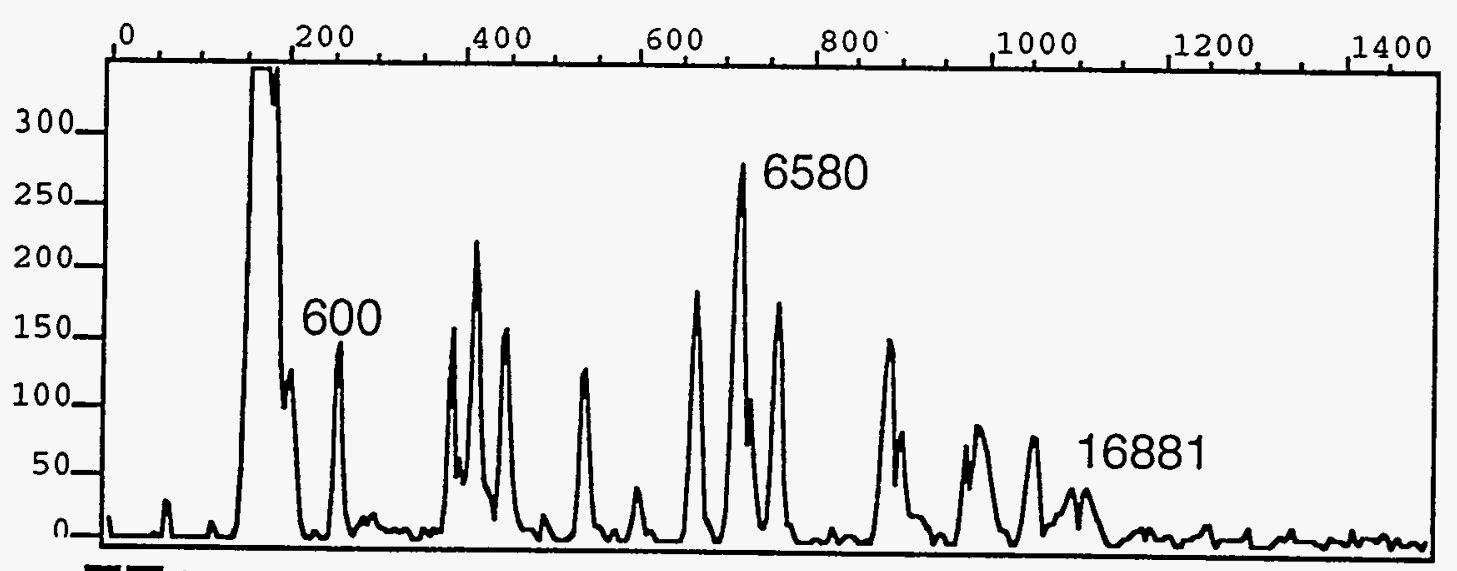

Lane 12: GS 30K

(c)

Figure 4: A comparison of separation of a $30 \mathrm{~K}$ base-pair fragment size standard in (a) a standard agarose slab gel ( $5 \mathrm{~mm}$ wide lanes and $4 \mathrm{~mm}$ thick gel), (b) glass microchannels ( $1 \mathrm{~mm}$ wide channels and $3 \mathrm{~mm}$ thick) and (c) plastic microchannels ( $1 \mathrm{~mm}$ wide channels and $3 \mathrm{~mm}$ thick). 
A small effort was initiated to demonstrate the feasibility of using alternative gels for increased resolution. We investigated the potential of using silica sol gels for fragment separations. While gel preparation and sample introduction appeared to be encouraging for gel comprised of tetramethoxysilane, we were unable to achieve detectable fragment separation. Further work in this area revealed a major shortcoming of gel swelling due to its hydrophilic nature. Such swelling leads to excessive sample dispersion and loss of resolution thus removing the promise of such materials for this application.

\section{Imaging Diagnostics of DNA in Microchannels}

We have developed a confocal fluorescence imaging system to study the transport and distribution of DNA fragments in micromachined channels. These measurements are important to understand what physical forces shape electrophoretic bands confined by a channel and also as an aid in the design of high throughput DNA sequencers.

\section{3,1 Confocal microscope detector design}

A confocal microscope detector ${ }^{4}$ was used to measure the spatial distribution of DNA in electrophoretic bands because of its high spatial resolution. A schematic of the optics used in the experiment is shown in Figure 5. An argon-ion laser was run at a wavelength of $488 \mathrm{~nm}$. The laser beam passed through a 50 percent beam splitter so that a helium-neon (HeNe) laser could be superimposed on it. This was particularly useful for aligning the fluorescence collection optics. The argon-ion laser beam then entered the lamp port of a Zeiss Axioplan microscope (the lamp optics had been removed), and was reflected by a dichroic beamsplitter through a Zeiss $32 \mathrm{X}$ magnification, $0.4 \mathrm{~N}$.A., infinite conjugate objective. The full width half maximum of the intensity profile of the focused beam in air was measured to be $1.8 \pm 2$ microns along both vertical and horizontal axis. These values were certainly larger in the polyacrylamide gel. The power of the argon-ion laser beam emerging from the microscope objective was approximately $0.5 \mathrm{~mW}$.

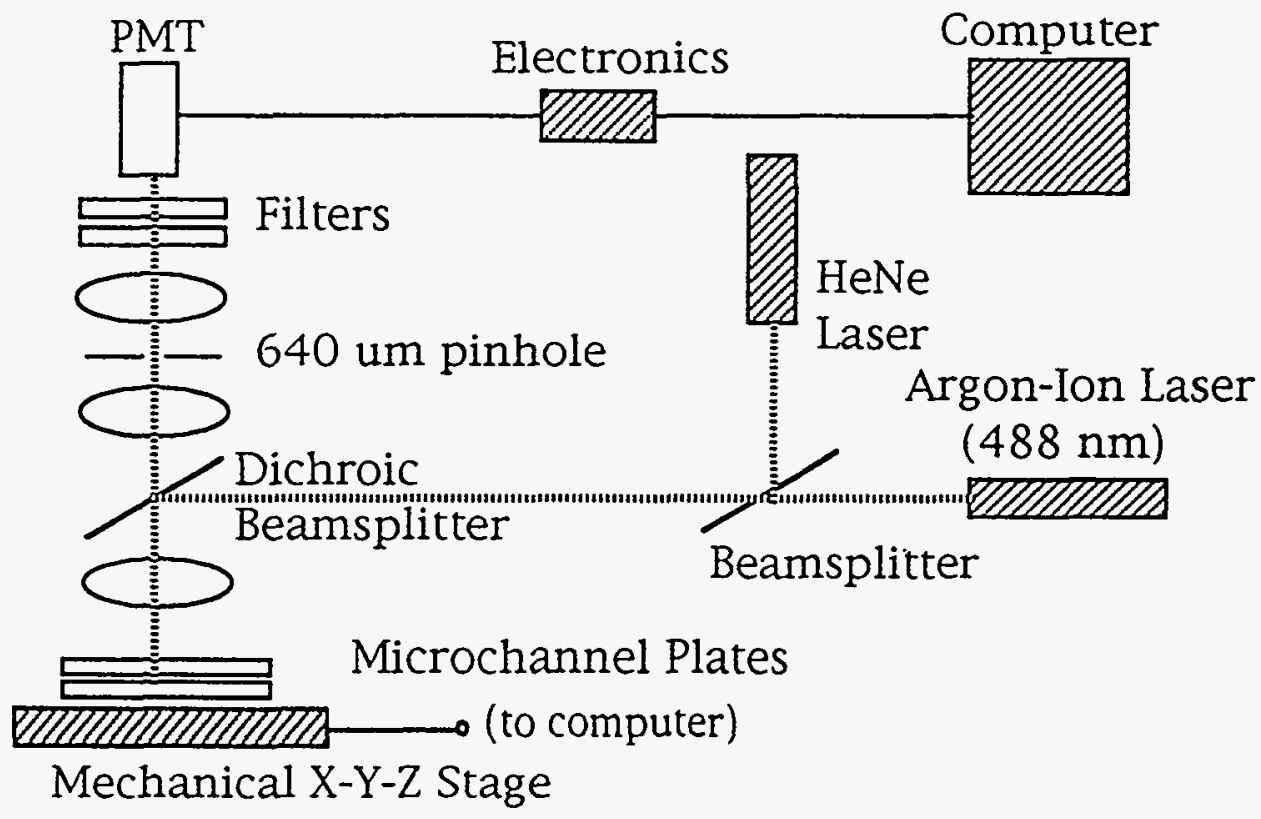

Figure 5. Schematic diagram of the confocal microscope used for profiling the distribution of DNA in microchannels. 
The fluorescence from the dye tagged DNA was collected by the same microscope objective, passed back through the dichroic beam splitter, through a $488 \mathrm{~nm}$ blocking filter (for eye safety), through the microscope tube lens, which focused the light through a 0.64 $\mathrm{mm}$ pinhole mounted on a precision $x-y-z$ translation stage. The addition of the pinhole narrowed the depth of focus of the microscope. The fluorescence then passed thorough a focusing lens, two $10 \mathrm{~nm}$ wide bandpass filters centered at $540 \mathrm{~nm}$ (corresponding to the "FAM" dye label in ABI TAQ) before finally impinging on the photocathode of a chilled Hammamatsu 943-02 photomultiplier tube. The signal from the photomultiplier tube was sent to a preamplifier, a discriminator, and then a frequency counter (a photon counting detection system; was used). The signal was typically integrated over times ranging from 0.1 to 2 seconds. The frequency counter output was sent to an IBM compatible 486, DX-2 computer. The microscope $\mathrm{x}-\mathrm{y}$ stage and $\mathrm{z}$ axis focus controller were controlled by computer via a GPIB interface. The electrophoresis plates were moved in discrete steps by the $\mathrm{x}-\mathrm{y}$ stage and focus controller, and data was taken while the plates were stationary, in between steps. The axial depth of focus of the confocal microscope detector was measured to have a full width half maximum of $33 \pm 3$ microns in air (adjusted for light with a wavelength of 540 $\mathrm{nm})$. This depth of focus was larger in the polyacrylamide gel.

\subsection{Measured DNA distribution in microchannels}

Figure 6 shows a linear scan taken across the three microchannels. The confocal microscope detector was positioned $25 \mathrm{~cm}$ from the channel load wells and approximately 200 microns from the bottom of the channels. The microscope $x-y$ stage moved the plates back and forth across the three channels and data was taken along each pass. DNA was only loaded into the middle channel. The data starts with a band composed of DNA fragments 221 nucleotides long. It took approximately 5 seconds for each scan across the 3 channels. The data shown is raw data, with no signal processing. The rectangular step seen across the three channels corresponds to the fluorescence of the gel (which is greater than that of the glass) in the microchannel. The signal due to the DNA is clearly seen in the middle channel atop the pedestal due to the fluorescence of the gel. The DNA is clearly peaked in the middle of the channel and confined away from the walls of the channel. During the experiment we looked at peaks with length ranging from 50 to 300 nucleotides and all the peaks showed an identical distribution of DNA in the microchannel.

These measurements show the DNA in the micromachined channels have peak intensity in the middle of the channel and are confined away from the walls. A number of physical mechanisms may be responsible for repelling the DNA from the microchannel walls such as the electrostatic force due to the field distribution in the channel, or some interaction between the DNA mobility and the thermal distribution in the microchannel. The DNA distribution could also be due to the shape of the loading well. Detailed modeling calculations will have to be made, accounting for these mechanisms before an accurate understanding of these observations can be made. 


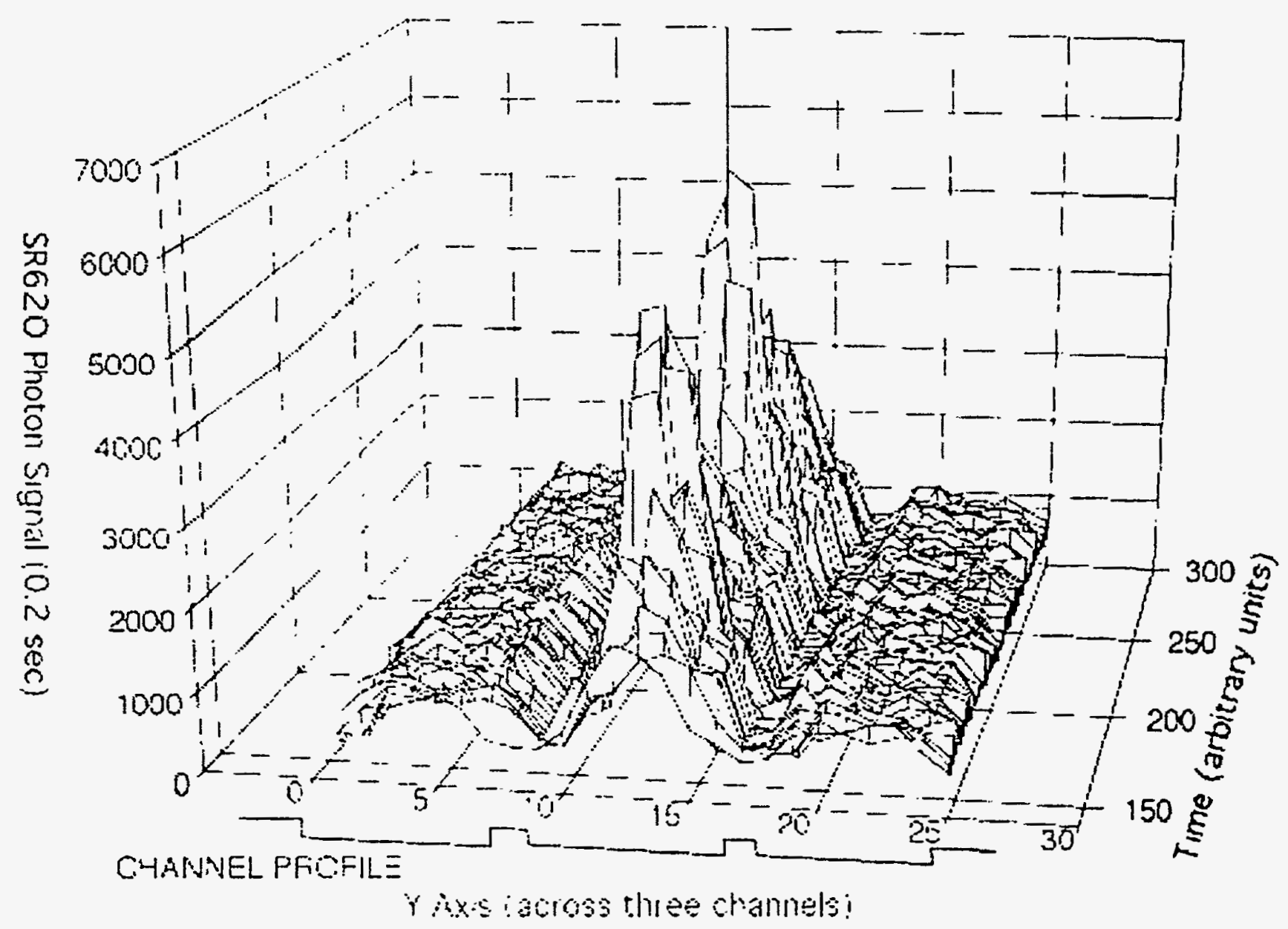

Figure 6. A linear scan across the three channels was taken over a period of time resulting in a record of several bands of DNA. The channel dimensions were $1.25 \mathrm{~mm}$ wide by $200 \mathrm{um}$ deep microchannel. DNA samples were loaded in only the center channel of three channels shown in the figure.

\section{Summary and Conclusions}

This work has demonstrated important microfabrication technologies for building high density arrays of microchannels capable of high resolution electrophoresis of DNA for both sequencing and large fragment separations. Chemical etching of glass substrates was found to be an efficient method to labricale arrays of microchannels with a surface finish adequate for DNA sequencing out to approximately 500 bases. Arrays having 48 microchannels were built and tested. Similarly, microchannels etched in glass produced good resolutions for large DNA fragment analysis and demonstrated the feasibility of a $5 \mathrm{X}$ increase in lane density over conventional systems. Using a scanning confocal microscope we developed, we 
have measured the distribution of DNA in microchannels and found the DNA to reside in the center of the glass channels away from the glass walls.

As the number of separation channels is increased, future efforts should focus on improvements in sample introduction. Manual sample introduction methods are not feasible. Additionally, large fragment separations of up to $100 \mathrm{~K}$ base pairs with a resolution of 1000 bases are desirable. Future efforts could explore alternating electric fields in microchannels as a way to increase separation of large fragment. 5,6 


\section{REFERENCES}

[1] Radola, Bertold, J. Electrophoresis Vol. 1, pg. 43-56, 1980.

[2] W. Ansorge and L. De Maeyer, Thermally Stabilized Very Thin (0.02-0.3 mm) Polyacrylamide Gels for Electrophoresis, J. of Chromatography, vol. 202, pg. 45-53, 1980.

[3] H. Drossman et. al, High-Speed Separations of DNA Sequencing Reactions by Capillary Electrophoresis, Anal. Chem., Vol. 62, pg. 900, 1990

[4] Xiahua C. Huang, Mark A. Quesada and Richard A. Mathies Anal Chem. Vol. 64, 967-972 (1992) "Capillary array electrophoresis using laser-excited confocal fluorescence detection.

[5] Schwartz, D.C. and Cantor, C.R., Cell, 1984, 37, 67-75.

[6] Turnel, C.,Brassard, E., Slater, G.W. and Noolandi, J., Nucl. Acids Res, 1990, 18, 569575. 